\title{
Variabilidade em Eremanthus erythropappus para resposta à inoculação micorrízica
}

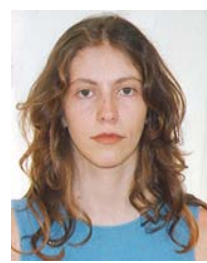

Ana C. da Silva ${ }^{1}$, Cenir T. Vieira ${ }^{1}$ \& Sebastião C. da S. Rosado ${ }^{1}$

1DCF/UFLA, CP 37, CEP 37200-000. Fone: (35) 3829-1431, E-mail: carol.sil@zipmail.com.br (Foto); cengflor@yahoo.com.br; scrosado@ufla.br

Protocolo 127 - 31/7/2003 - Aprovado em 14/1/2005

\begin{abstract}
Resumo: Este estudo teve como objetivo avaliar a variação entre e dentro de procedências de candeia (Eremanthus erythropappus) para resposta à inoculação com fungos micorrízicos. Foram coletadas sementes de seis matrizes localizadas em duas procedências do sul do Estado de Minas Gerais (três de São Tomé das Letras e três de Carrancas) e, dessas, produzidas mudas que foram arranjadas em parcela subdividida com quatro blocos casualizados, cujas parcelas constituíram os tratamentos com e sem inoculação micorrízica, e a subparcela, o genótipo. Do primeiro ao oitavo mês após a repicagem para tubetes, foram coletados os dados de altura, diâmetro e taxa de sobrevivência das mudas no viveiro. Constatou-se que há variações para a característica altura entre as duas procedências, entre os tratamentos de inoculação e para a interação procedência inoculação. Apurou-se ainda que não há diferenças significativas entre as progênies mas, sim, diferença para o tratamento de inoculação com micorriza, somente para a característica altura.
\end{abstract}

Palavras-chave: fungos micorrízicos, candeia, variação genética

\section{Variability in Eremanthus erythropappus in response to mycorrhizal inoculation}

\begin{abstract}
This study had the objective to estimate the variations among and within origins of candeia (Eremanthus erythropappus) in response to inoculation with mycorrhizal fungi. Openpollinated seeds were collected from six matrix trees of two distinct populations: São Tomé das Letras and Carrancas, in the States of Minas Gerais, Brazil. The seedlings produced were arranged in split plot in four randomized blocks, where the split plots constituted of treatments with or without mycorrhizal inoculation and the plot which the genotype. From the first to the eighth month after transfering seedlings into containers the data related to height, diameter and survival rate of seedlings in the nursery were collected. In the analysis of variance, there were variations for height characteristic between the two origins, among the inoculation treatments and for the interaction origin inoculation. The analysis among the progenies showed that there were no significant differences among origins, but differences were observed for the inoculation treatment with regard to the height characteristic.
\end{abstract}

Key words: mycorrhizal fungi, candeia, genetic variation

\section{INTRODUÇÃO}

A degradação dos solos ocorre quando suas condições edáficas e qualidade biológica são reduzidas pela atividade humana, a um ponto em que o seu restabelecimento não se dá de forma natural, necessitando de ações antrópicas. Neste sentido, o atual desafio da silvicultura brasileira é a produtividade florestal em áreas em que os efeitos dos estresses bióticos e abióticos no crescimento e desenvolvimento das árvores, são bastante acentuados (Rosado, 1996). As estratégias mais promissoras para vencer este desafio incluem os programas de melhoramento genético e a utilização dos fungos micorrízicos, capazes de amenizar o impacto de fatores estressantes (Marx, 1991).

Através da seleção de genótipos que apresentam boa capacidade de absorção e utilização dos nutrientes do solo, o melhoramento genético pode facilitar e permitir o cultivo de árvores em sítios de baixa fertilidade, promovendo a melhoria do estado nutricional e, conseqüentemente, o aumento da produtividade florestal (Goddard \& Hollis, 1984). Portanto, a busca de genótipos superiores, aqueles capazes de sobreviver, 
crescer e produzir em sítios desfavoráveis torna-se de grande importância econômica e ambiental (Rosado, 1996).

$\mathrm{Na}$ aplicação de fungos micorrízicos, uma melhoria da eficiência simbiótica poderá, de forma complementar ao referido melhoramento, permitir uma utilização melhor desses sítios, considerando-se os efeitos da simbiose no aumento da absorção e transporte de água e nutrientes do solo para as raízes (Skinner \& Bowen, 1974a, 1974b), bem como pelo aumento da tolerância à acidez, toxidez de metais pesados e temperaturas elevadas do solo (Marx, 1991) e da resistência às doenças do sistema radicular (Kope et al., 1990).

Além desses benefícios, a existência de significativa variação intra-específica em várias espécies de plantas quanto à dependência micorrízica (Menge et al., 1978; Rajapakse \& Miller Júnior, 1988), permite prever que o cultivo de genótipos de plantas (procedências e progênies) que possuem alto grau de dependência micorrízica, tem alta probabilidade de insucesso quando as condições ambientais se tornarem adversas e se suas raízes não estiverem adequadamente colonizadas pelo parceiro fúngico. Como conseqüência disso, haverá aumento da interação genótipo-ambiente, resultando numa redução do ganho genético esperado pela seleção dos melhores genótipos de plantas.

Em áreas degradadas há dificuldade de indicação de espécies florestais para serem cultivadas alcançando as metas da reabilitação ambiental. Dentre as poucas espécies com potencial satisfatório, destaca-se a candeia (Eremanthus erythropappus) que, além de ser uma espécie pioneira, ocorre naturalmente em solos pobres, arenosos ou pedregosos, apresentando crescimento inicial acelerado (Rizzini, 1981).

A candeia pode, ainda, aumentar a renda de pequenos proprietários rurais, pois sua madeira possui alta durabilidade natural, sendo comumentemente usada para moirões de cerca, além de possuir óleo essencial de uso farmacológico (Rizzini, 1981).

Mesmo em espécies resistentes a condições ambientais adversas, como é o caso da candeia, para o alcance de níveis adequados de estabilidade fenotípica no crescimento em áreas degradadas, pode haver necessidade de seleção de procedências e progênies mais adaptadas a essas condições, além da inoculação com fungos micorrízicos que maximizem o seu potencial restaurador em sítios de baixa qualidade.

Assim, o objetivo deste trabalho foi avaliar a variação entre e dentro de procedências de candeia (Eremanthus erythropappus) quanto à capacidade de crescimento e desenvolvimento inicial no viveiro; verificar se existe associação com os fungos micorrízicos arbusculares; e avaliar a possibilidade de se selecionar genótipos de candeia com melhor resposta aos benefícios da simbiose, para serem cultivados em projetos de recuperação de áreas degradadas e em reflorestamentos de sítios de baixa qualidade.

\section{MATERIAL E MÉTODOS}

Utilizam-se genótipos provenientes de seis progênies de meio-irmãos de polinização livre, coletados em duas populações naturais de candeia (procedências) localizadas nos municípios de São Tomé das Letras (latitude - $21^{\circ} 72$ ' 2", longitude - 44 $98^{\prime} 5^{\prime \prime}$ e altitude $1300 \mathrm{~m}$ ) e Carrancas (latitude - $21^{\circ} 48^{\prime} 8^{\prime \prime}$, longitude $44^{\circ} 64^{\prime} 3$ ” e altitude $1000 \mathrm{~m}$ ), no sul de Minas Gerais. Em cada procedência foram coletadas três progênies, em um total de seis progênies, originadas de árvores matrizes distanciadas entre si de pelo menos $100 \mathrm{~m}$.

As sementes foram semeadas a lanço, em sementeiras constituídas por uma mistura de $70 \mathrm{~L}$ de esterco de curral peneirado, $70 \mathrm{~L}$ de palha de arroz carbonizada e $200 \mathrm{~L}$ de terra de barranco peneirada.

Após atingir o crescimento inicial, as mudas foram repicadas para tubetes de polietileno rígido escuro, de $250 \mathrm{~cm}^{3}$. O substrato dos tubetes foi esterilizado com brometo de metila e recebeu as seguintes misturas: $200 \mathrm{~L}$ de esterco de curral peneirado; $100 \mathrm{~L}$ de vermiculita; $150 \mathrm{~L}$ de casca de arroz carbonizada; $50 \mathrm{~L}$ de terra de barranco peneirada; $250 \mathrm{~g}$ de sulfato de amônio; $100 \mathrm{~g}$ de cloreto de potássio; $100 \mathrm{~g}$ de adubo com a formulação contendo os micronutrientes $\mathrm{Zn} \mathrm{9 \% ,} \mathrm{B} \mathrm{1,8 \% ,}$ $\mathrm{Cu}$ 0,8\%, Fe 3\%, Mn 2\% e Mo 0,1\%; e $1 \mathrm{~kg}$ de adubo com a formulação contendo os nutrientes Ca 20\%, B 0,1\%, Mn 0,12\%, Mo 0,006\%, Mg 7\%, Zn 0,55\%, Cu 0,5\% e S 6\%.

Metade das mudas repicadas foi inoculada com uma mistura de fungos micorrízicos arbusculares, na proporção: Glomus etunicatum 70\%, Glomus occultum 25\%, Acaulospora scrubiculata $5 \%$, e a outra metade recebeu o filtrado.

Do primeiro ao oitavo mês após a repicagem em tubetes, avaliou-se a altura das plantas, com o auxílio de uma régua graduada em centímetro e o diâmetro do caule à altura do solo, medido com o auxílio de um paquímetro, que fez leituras em milímetro.

$\mathrm{O}$ arranjo experimental foi em parcelas subdivididas com quatro blocos ao acaso, oito plantas por parcela e dois tratamentos: com e sem inoculação micorrízica. No primeiro estudo, a parcela se compunha dos tratamentos com e sem inoculação com micorriza e a subparcela pelas duas procedências (São Tomé das Letras e Carrancas); já no segundo estudo, a subparcela foi substituída pelas seis progênies. Os dados foram submetidos à análise de variância, seguindo-se o procedimento análise de parcela subdividida do programa GENES - Genética Quantitativa e Estatística Experimental V.5 (Cruz, 2001). em que o modelo biométrico utilizado foi:

A dependência micorrízica que, segundo Hetrick (1988) é o grau no qual a planta depende do parceiro fúngico para obter seu melhor crescimento ou produção a dado nível de fertilidade do solo, pode ser obtida pela relação matemática entre o crescimento ou produção das plantas micorrizadas e o apresentado pelas plantas não micorrizadas (Menge et al., 1978; Siqueira \& Franco, 1988). A fórmula usada para se calcular a dependência micorrízica, foi:

$$
\mathrm{DM}=\frac{\mathrm{MI}-\mathrm{MN}}{\mathrm{MN}} \mathrm{x} 100
$$

em que:

MI - mudas inoculadas; MN: mudas não inoculadas. 


\section{RESULTADOS E DISCUSSÃO}

\section{Estudo 1. Variações entre as procedências}

Os resultados obtidos da análise de variância entre as procedências (Pc) de São Tomé das Letras (STL) e Carrancas (CAR), realizada no oitavo mês após a repicagem das mudas para tubetes (Tabela 1), mostram a ocorrência de variações significativas a $5 \%$ de probabilidade somente para a característica altura das mudas a qual, portanto, pode ser usada em programas de seleção de procedência de candeia.

Tabela 1. Resumo das análises de variância para as procedências (Pc) de São Tomé das Letras e Carrancas, para as características diâmetro $(\mathrm{mm})$, altura $(\mathrm{cm})$ e taxa de sobrevivência das mudas (\%), aos oito meses após a repicagem

\begin{tabular}{|c|c|c|c|c|}
\hline \multirow{2}{*}{ FV } & \multirow{2}{*}{ GL } & \multicolumn{3}{|c|}{ QM } \\
\hline & & Diâmetro & Altura & Sobrevivência \\
\hline Blocos & 3 & 0,0558 & 0,8489 & 36,0383 \\
\hline Inoculação & 1 & $0,0625^{\mathrm{NS}}$ & $4,1006^{* *}$ & $720,9225^{\text {NS }}$ \\
\hline Erro a & 3 & 0,0158 & 0,4106 & 142,3175 \\
\hline $\mathrm{Pc}$ & 1 & $0,0025^{\mathrm{NS}}$ & $4,7306^{*}$ & $205,9225^{\mathrm{NS}}$ \\
\hline Pc x inoculação & 1 & $0,0025^{\mathrm{NS}}$ & $1,1556^{*}$ & $15,21^{\mathrm{NS}}$ \\
\hline Erro b & 6 & 0,0092 & 0,1681 & 79,5379 \\
\hline
\end{tabular}

Para os tratamentos com e sem inoculação com micorriza e para a interação entre procedência/inoculação, também ocorreram variações significativas para a altura, mostrando que a micorrização tem efeito sobre referida característica, além de determinada procedência responder melhor à inoculação.

Na Figura 1 estão representadas as médias dos diâmetros $(\mathrm{mm})$, altura das mudas (cm) e taxa de sobrevivência (\%) das procedências de STL e de CAR, medidas aos oito meses, para os tratamentos com e sem inoculação com micorriza.

Tanto o diâmetro como a altura mostraram valores superiores para os tratamentos com inoculação com micorriza, porém somente a característica altura obteve variação significativa na análise estatística.

O tratamento com inoculação com micorriza obteve maior taxa de sobrevivência das mudas nas duas procedências que o tratamento sem inoculação; no entanto, a análise de variância mostrou que essas diferenças não são significativas. As mudas da procedência de São Tomé das Letras apresentaram taxa de sobrevivência maior que as mudas de Carrancas. Essas diferenças também não foram significativas na análise de variância.

Analisou-se a dependência micorrízica para a altura (Figura 2), por esta característica apresentar variações significativas na inoculação (Tabela 1). Observa-se que referida dependência é maior para a procedência de CAR que para a procedência de STL. Em condições de campo, CAR deve ser inoculada para atingir seu máximo crescimento ou produção. A procedência de STL possui baixa dependência micorrízica e, portanto, a relação custo/benefício pode inviabilizar a inoculação; além disso, observa-se, ainda na Figura 1, que a procedência de

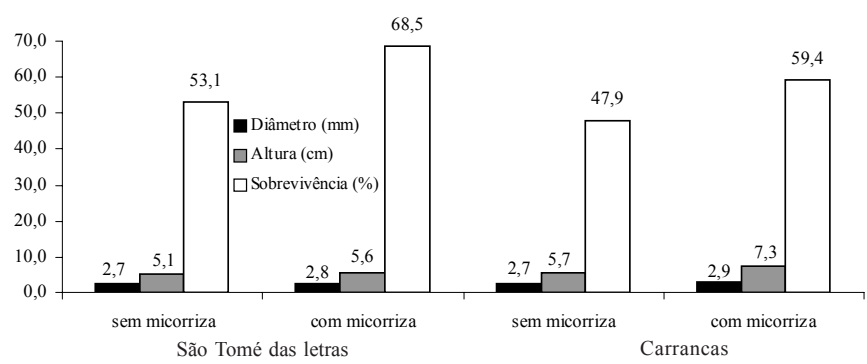

Figura 1. Distribuição das médias do diâmetro $(\mathrm{mm})$, altura $(\mathrm{cm})$ e taxa de sobrevivência (\%) das procedências de São Tomé das Letras e Carrancas, com e sem inoculação com micorriza, medidas aos oito meses após a repicagem

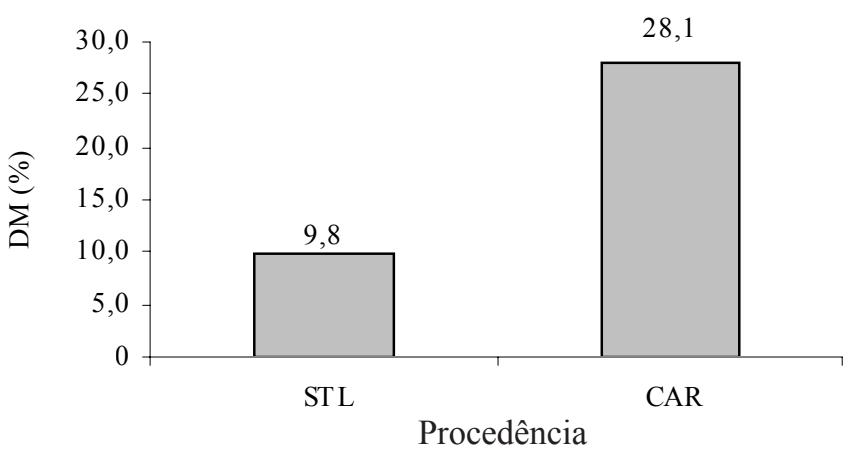

Figura 2. Dependência micorrízica (DM) para a característica altura, entre as procedências de São Tomé das Letras (STL) e Carrancas (CAR), medidas aos oito meses após a repicagem

CAR não inoculada apresenta maior crescimento em altura que a procedência de STL inoculada, viabilizando a utilização da procedência de Carrancas, mesmo quando não inoculada.

$\mathrm{Na}$ Figura 3 verificam-se os crescimentos em diâmetro e em altura, e a taxa de sobrevivência das mudas, medidos do primeiro ao oitavo mês após a repicagem para tubetes. As mudas inoculadas foram superiores em diâmetro que as não inoculadas, assim como as mudas da procedência de Carrancas, que se mostram superiores às mudas da procedência de São Tomé das Letras.

O crescimento em altura mostrou o mesmo padrão: as mudas inoculadas obtiveram maior crescimento em altura que as não inoculadas e as mudas da procedência de Carrancas obtiveram maior crescimento que as mudas de São Tomé das Letras.

No gráfico da taxa de sobrevivência (Figura 3) vê-se que, a partir do terceiro mês, há forte aumento da mortalidade das mudas devido à contaminação do experimento pelo fungo Fusarium sp. No oitavo mês, as mudas da procedência de São Tomé das Letras mostraram maior taxa de sobrevivência que as mudas de Carrancas. O tratamento com inoculação obteve maior taxa de sobrevivência que o tratamento sem inoculação, durante quase todo o período.

\section{Estudo 2. Variações entre as progênies}

Os resultados da análise de variância entre todas as progênies dentro das duas procedências (São Tomé das Letras e Carrancas) e entre os tratamentos com e sem inoculação com micorriza, encontram-se na Tabela 2. Não houve variações significativas entre as progênies nem para a interação progênie/ inoculação, para as características avaliadas. A seleção de 

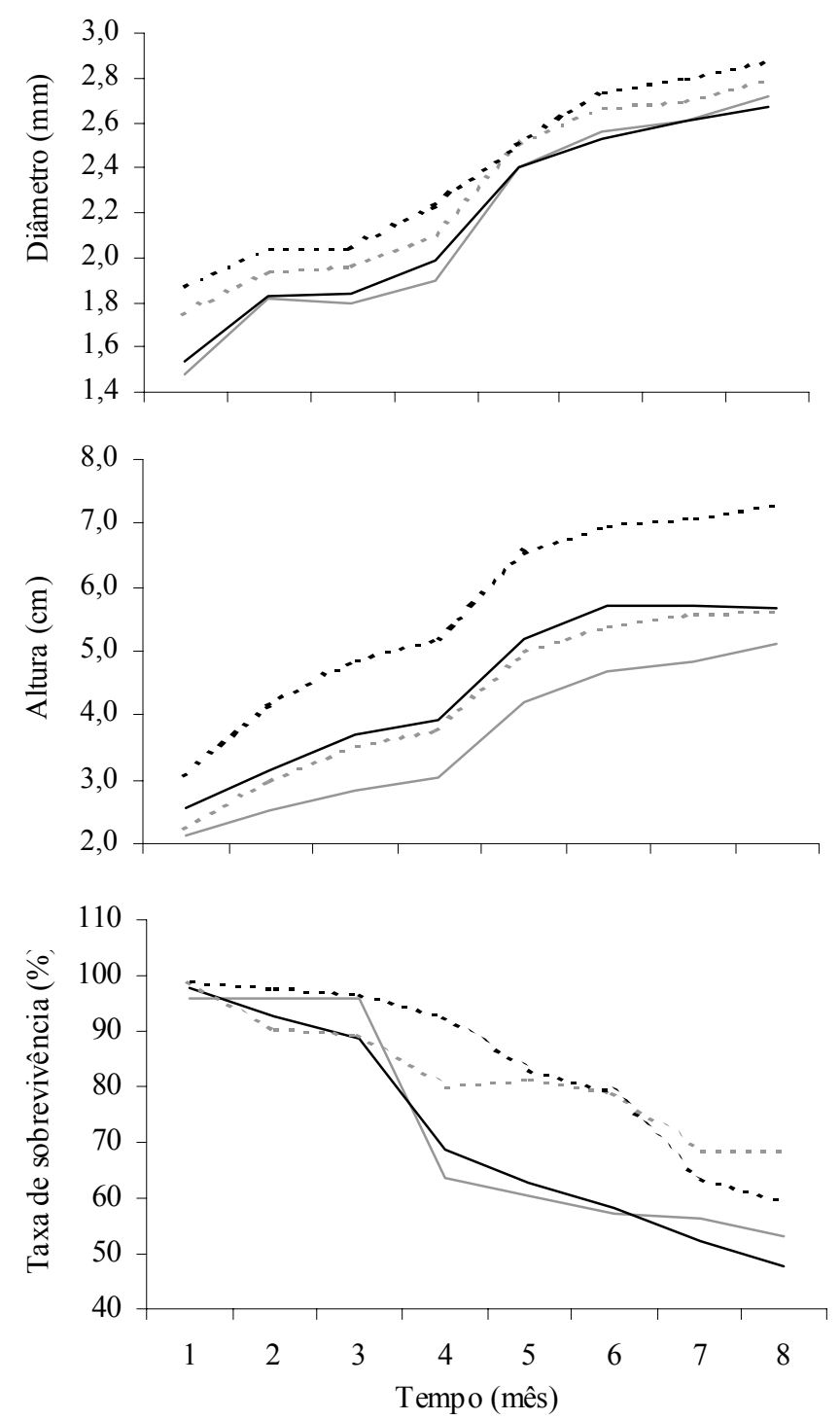

Figura 3. Distribuição das médias dos crescimentos em diâmetro $(\mathrm{mm})$ e altura $(\mathrm{cm})$, e taxa de sobrevivência $(\%)$, das procedências de São Tomé das Letras (em cinza) e de Carrancas (em preto), inoculadas (tracejado) e não inoculadas (linha contínua), medidas do primeiro ao oitavo mês após a repicagem

progênies de candeia não é, portanto, viável, pois só é possível realizar o melhoramento quando há variabilidade genética.

$\mathrm{Na}$ análise entre os tratamentos com e sem inoculação, apenas a característica altura obteve variações significativas, mostrando que a inoculação das progênies é necessária para aumentar o crescimento em altura das mudas.

A Figura 4 indica as distribuições gráficas das médias dos valores de diâmetro, altura e taxa de sobrevivência de todas as progênies inoculadas e não inoculadas, medidas no oitavo mês após a repicagem. As mudas das progênies dentro da procedência de Carrancas (CAR) obtiveram maiores valores de diâmetro quando inoculadas, e as mudas das progênies dentro da procedência de São Tomé das Letras (STL), maiores valores quando não inoculadas, porém essas diferenças não foram significativas na análise estatística.
Tabela 2. Resumo das análises de variância conduzidas para todas as progênies $(\mathrm{P})$ para as características diâmetro $(\mathrm{mm})$, altura $(\mathrm{cm})$ e taxa de sobrevivência das mudas (\%), no oitavo mês após a repicagem

\begin{tabular}{lclll}
\hline \multirow{2}{*}{ FV } & \multirow{2}{*}{ GL } & \multicolumn{3}{c}{ QM } \\
\cline { 3 - 5 } & & Diâmetro & Altura & Sobrevivência \\
\hline Blocos & 3 & 0,3774 & 2,6455 & 142,1441 \\
Inoculação & 1 & $0,0052^{\mathrm{NS}}$ & $6,3075^{*}$ & $1435,5469^{\mathrm{NS}}$ \\
Erro a & 3 & 0,2630 & 0,5986 & 584,8524 \\
$\mathrm{P}$ & 5 & $0,2929^{\mathrm{NS}}$ & $10,0878^{\mathrm{NS}}$ & $284,5052^{\mathrm{NS}}$ \\
$\mathrm{P}$ x inoculação & 5 & $0,1502^{\mathrm{NS}}$ & $2,157^{\mathrm{NS}}$ & $404,2969^{\mathrm{NS}}$ \\
Erro b & 33 & 0,1989 & 1,4781 & 347,8733 \\
\hline NS - Não significativo pelo teste de F $(\mathrm{p}>0,05)$. * Significativo pelo teste de F $(\mathrm{p}<0,05)$
\end{tabular}
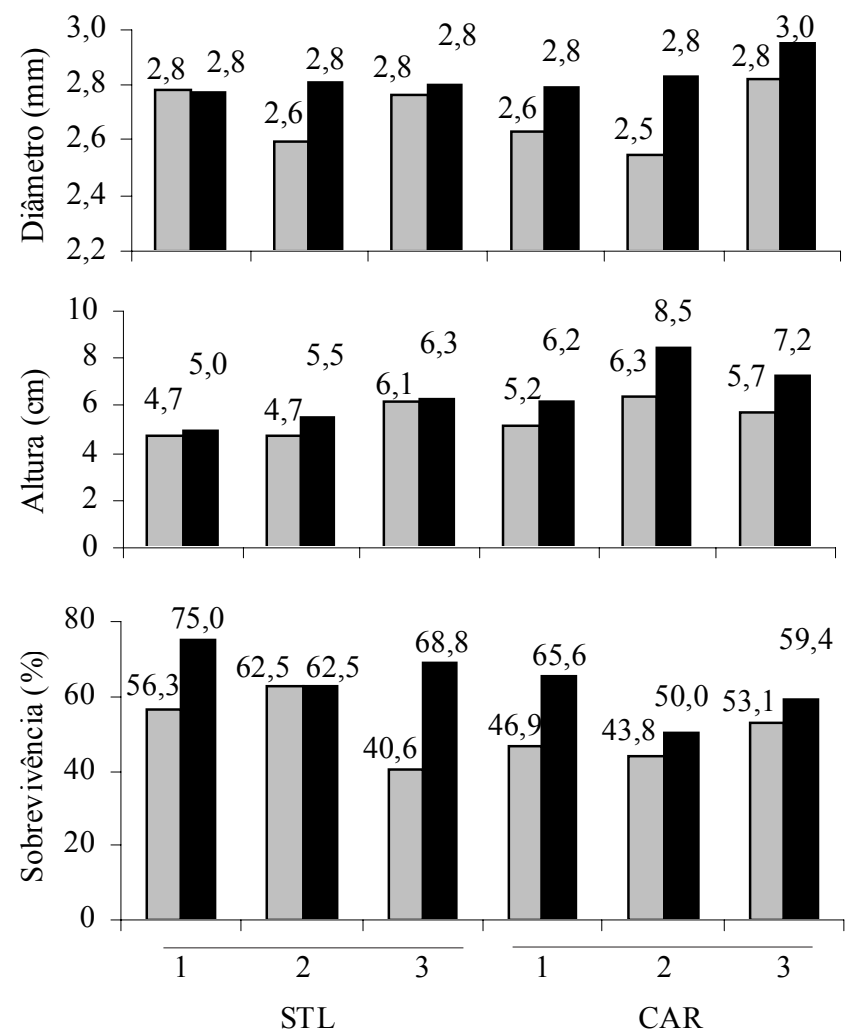

Figura 4. Diâmetro (mm), altura $(\mathrm{cm})$ e taxa de sobrevivência (\%) entre progênies dentro das procedências de São Tomé das Letras (STL) e Carrancas (CAR), com inoculação (em preto) e sem inoculação micorrízica (em cinza), medidos aos oito meses após a repicagem

Verifica-se, no gráfico da altura (Figura 4) que a progênie 2, da procedência de CAR, se destaca com a maior média, mesmo sem inoculação, e alto ganho, quando inoculada. $\mathrm{Na}$ análise estatística a variação em altura não mostrou diferenças significativas entre as progênies, porém, entre os tratamentos de inoculação, ocorreu variação a 5\% de probabilidade.

Embora as diferenças entre as progênies e o tratamento com inoculação tenham mostrado maior taxa de sobrevivência das mudas (Figura 4), esta característica não indicou significância nas análises de variância, entre as progênies e os tratamentos.

Calculou-se a dependência micorrízica para a característica altura (Figura 5), pois esta mostrou diferenças significativas na análise de variância entre os tratamentos de inoculação 


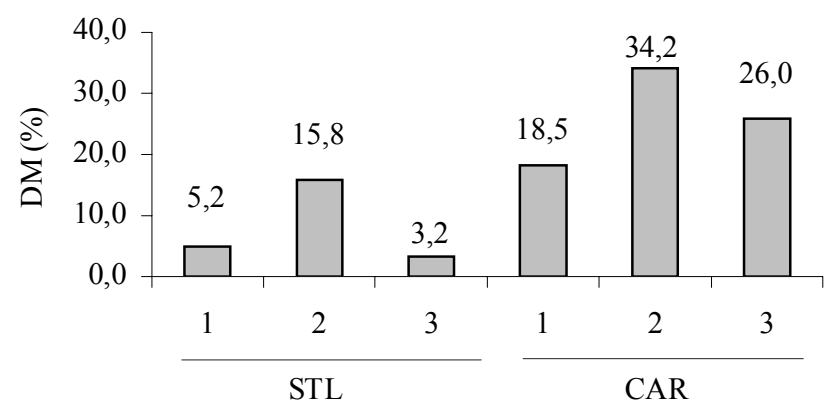

Figura 5. Dependência micorrízica (DM) para a característica altura, para as progênies de São Tomé das Letras (STL) e Carrancas (CAR), medida aos oito meses após a repicagem

(Tabela 2). As progênies dentro da procedência de STL possuem baixos valores de dependência micorrízica, enquanto as progênies dentro da procedência de CAR obtiveram altos valores de dependência micorrízica (Figura 5) e ganhos consideráveis em altura, quando inoculadas (Figura 4), principalmente a progênie 2 , que possui dependência micorrízica de 34,2\% (Figura 5).

A Figura 6 oferece o crescimento em diâmetro e altura e a taxa de sobrevivência de todas as progênies medidas do primeiro ao oitavo mês após a repicagem das mudas, mostrando
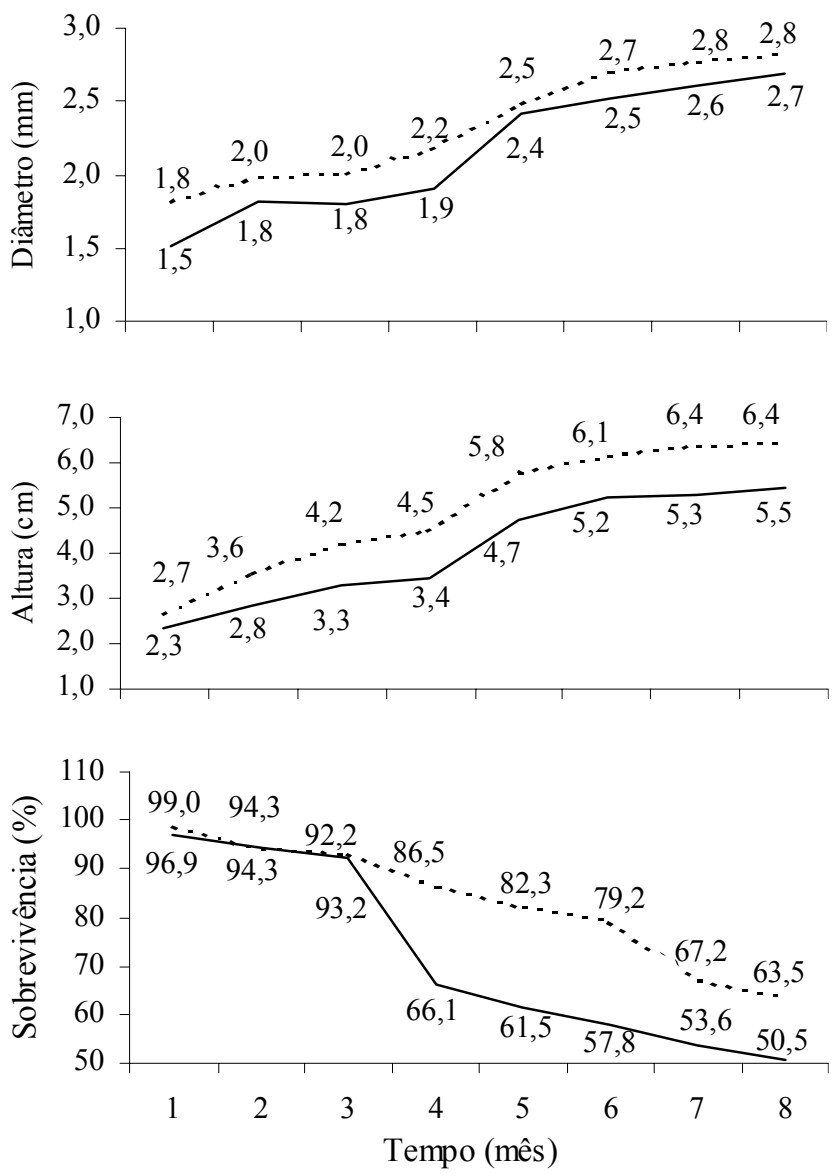

Figura 6. Distribuição das médias dos crescimentos em diâmetro $(\mathrm{mm})$ e altura $(\mathrm{cm})$, e taxa de sobrevivência (\%), de todas as progênies, inoculadas (em tracejado) e não inoculadas (em linha contínua) com micorriza, medidas do primeiro ao oitavo mês após a repicagem as diferenças entre o crescimento com e sem o tratamento de inoculação. Nos gráficos, as mudas que receberam a inoculação obtiveram maior incremento em diâmetro e altura, que as não inoculadas.

A taxa de sobrevivência indica que, a partir do terceiro mês, as mudas apresentaram alta taxa de mortalidade, devido à contaminação pelo fungo Fusarium $\mathrm{sp}$. De acordo com o gráfico, as mudas mais resistentes à mortalidade foram as que receberam tratamento com inoculação, indicando o benefício da micorrização na redução dos efeitos de fungos patogênicos. Na literatura, esse tipo de benefício foi registrado por Zambolim (1987), Kope et al. (1990) e Brundrett (1991).

A Figura 7 representa mudas inoculadas e não inoculadas com micorriza, mostrando o incremento em altura das mudas, quando inoculadas. Este maior incremento nas mudas inoculadas mostrou variações significativas, tanto no estudo 1 , entre as procedências, quanto no estudo 2 , entre as progênies sendo, portanto, necessária a inoculação quando se deseja maior crescimento em altura das mudas.

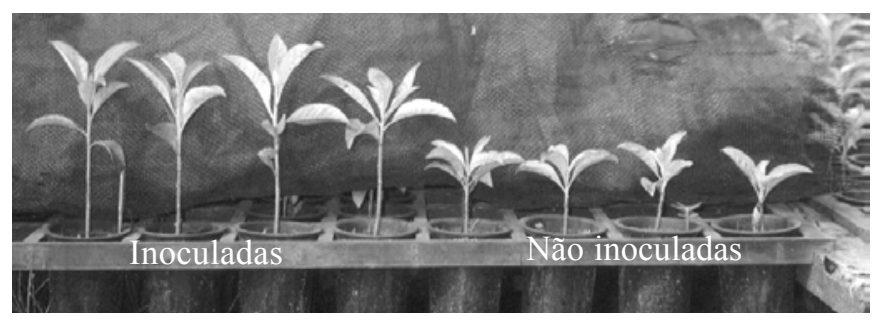

Figura 7. Mudas inoculadas e não inoculadas com micorriza

Vasconcelos et al. (2001), estudando o crescimento da candeia (Eremanthus erythropappus) em rejeitos de mineração da pedra São Tomé com ou sem adubação e com mudas inoculadas ou não inoculadas com fungos micorrízicos, concluíram haver necessidade de adubação e de inoculação das mudas, pois elas apresentaram maior crescimento em altura e também maior produção de biomassa, quando adubadas e inoculadas.

\section{CONCLUSÕES}

1. Existem variações significativas entre as procedências de São Tomé das Letras e Carrancas, apenas para a característica altura das mudas.

2. A candeia pode, portanto, ser usada em programas de melhoramento genético, quando se deseja selecionar procedência quanto à altura.

3. Não houve diferenças significativas entre todas as progênies nas características avaliadas, impossibilitando sua seleção.

4. Entre os tratamentos com e sem inoculação com micorriza houve diferenças significativas entre as procedências de São Tomé das Letras e Carrancas e entre todas as progênies, para a característica altura, mostrando ser a inoculação fator importante quando se deseja aumentar o crescimento de mudas de candeia. 
5. Houve incremento ou diminuição da dependência micorrízica das mudas para a característica altura, de acordo com a procedência de onde foram coletadas as sementes.

\section{AGRADECIMENTOS}

Ao Conselho Nacional de Desenvolvimento Científico e Tecnológico $(\mathrm{CNPq})$ pelo apoio financeiro à pesquisa.

\section{LITERATURA CITADA}

Brundrett M.C. Mycorrhizas in natural ecosystems. In: Macfayden A., Begon M.; Fitter A.H.; eds. Advances in ecological research, London, v. 21, p.171-313. 1991.

Cruz, C.D. Programa Genes - Versão Windows. 20.ed. Viçosa: Editora UFV, 2001.648p.

Goddard, R.E.; Hollis, C.A. The genetic basic of forest tree nutrition. In: Bowen, G.D.; Nambiar, K.S. (eds.). Nutrition of plantation forests. London: Academic Press, 1984. p.237-258.

Hetrick, B.A.D. Acquisition of phosphorus by VA mycorrhizal fungi and the growth responses of their host plants. In: Boddy, L.; Marchant, R.; Read, D.J. (eds.). Nitrogen, phosphorus and sulphur utilization by fungi. Cambridge, 1988. p.204-225.

Kope, H.H.; Tsantrizos, Y.S.C; Fortin, J.A.; Ogilvie, K.K. phydroxybenzoylformic and (R)-(-)-p-hydroxymandelic acid, two antifungal compounds isolated from liquid culture of the ectomycorrhizal fungus Pisolithus arhizus. Canadian Journal of Microbiology, Ottawa, v.37, n.4, p.258-264, 1990.
Marx, D.H. Forest application of the ectomycorrhizal fungus Pisolithus tinctorius. Stockholm: The Marcus Wallenberg Prize, 1991.36p.

Menge, J.A.; Johnson, E.L.V.; Platt, R.G. Mycorrhizal dependency of several citrus cultivars under three nutrient regimes. New Phytologist, London, v.81, n.3, p.553-558, 1978.

Rajapakse, S.; Miller Júnior, J.C. Relationship between cowpea root systems and mycorrhizal dependency. Hort Science, Alexandria, v.23, n.3, p.568-570, 1988.

Rizzini, C.T. Árvores e madeiras úteis do Brasil: manual de dendrologia brasileira. São Paulo: Edgard Blücher, 1981. 304p.

Rosado, S.C.S. Genética quantitativa aplicada em fungos ectomicorrízicos. In: Siqueira, J.O. (ed.) Avanços em fundamentos e aplicação de micorrizas. Lavras: UFLA, 1996. cap.5, p.101-133.

Siqueira, J.O.; Franco, A.A. Biotecnologia do solo: fundamentos e perspectivas. Lavras: MEC/ESAL/FAEPE/ ABEAS, 1988. 235p.

Skinner, M.F.; Bowen, G.D. The uptake and translocation of phosphate by mycelial strands of pine mycorrhizas. Soil Biology and Biochemistry, Oxford, v.6, n.1, p.53-56, 1974a.

Skinner, M.F.; Bowen, G.D. The penetration of soil by mycelial strands of ectomycorrhizal fungi. Soil Biology and Biochemistry, Oxford, v.6, n.1, p.437-457, 1974 b.

Vasconcelos, F.C.W.; Scotti, M.R.; Pinto, C.L.L. Recomposição vegetal em pilhas de quartzito sericítico, São Tomé das Letras, MG. Semearh - Revista de Saneamento, Meio Ambiente e Recursos Hídricos, Belo Horizonte, v.2, n.3, p.7-9, 2001.

Zambolim, L. Tolerância de plantas micorrizadas a fitonematóides. In: Reunião Brasileira sobre Micorrizas, 2, 1987, São Paulo. Resumos... São Paulo: USP, 1987. p.103. 